\title{
Analysis of Russia's Innovative Position in the Asia-Pacific Economic Cooperation
}

\author{
Valeriy Smirnov ${ }^{1, *}$, Denis Osipov ${ }^{1}$, Vasiliy Ashmarin ${ }^{1}$, Anatoliy Blokhintsev ${ }^{1}$ and Elena Grigorieva ${ }^{1}$ \\ ${ }^{1}$ Chuvash State University named after I.N. Ulyanova, Moskovsky prospekt, 15, 428015, Cheboksary, \\ Russia, \\ *Corresponding author
}

Keywords: Asia-Pacific Economic Cooperation, Innovative Position, Clusters, Competition, Systematic Approach.

Abstract: The subject of the study is the innovative development of Russia. The topic of the study is the analysis of Russia's innovative position in the Asia-Pacific economic cooperation (APEC) format. The aim of the paper is to identify significant factors that determine the innovative position of Russia in APEC. The study is based on a systematic approach using statistical and cluster analysis. The article highlights the problems of innovative development of the world economy and APEC countries caused by the slowdown in the growth of world trade and increased global competition. These problems focus on the analysis of the innovative position of countries in the format of international cooperation organizations. The reasons of formation are revealed, the purpose is distinguished and the principles of functioning of APEC are defined. Methodological provisions of innovative development of APEC countries are considered. The cluster analysis revealed multicomponent and two-component clusters as well as the reasons for their formation and principles of functioning. Application of cluster analysis revealed Russia's innovative position in the multicomponent cluster of APEC countries and strong groups of links. Application of statistical analysis to dynamics of factors of innovative development of the countries allowed to reveal the innovative position of Russia and risk of loss of competitive advantages.

\section{Introduction}

Analysis of the innovative position of countries makes it possible to identify not only internal problems but also structural changes in the world economy. According to the Global Innovation Index (GII), “Cornell INSEAD WIPO (World Intellectual Property Organization)” [1] the world leaders in GII 2019 innovation are:

1) top innovative economies by region: North America - 1. USA, 2. Canada; Europe - 1. Switzerland, 2. Sweden, 3. Netherlands; North Africa and West Asia - 1. Israel, 2. Cyprus, 3. United Arab Emirates; South-East - 1. Singapore, 2. The Republic Of Korea, 3. Hong Kong, China; Latin America and the Caribbean - 1. Chile, 2. Costa Rica, 3. Mexico; Africa south of Sahara - 1. South Africa, 2. Kenya, 3. Mauritius; Central and South Asia - 1. India, 2. Iran, 3. Kazakhstan; 
2) top innovative economies by income groups: high - 1. Switzerland, 2. Sweden, 3. USA; upper medium - 1. China, 2. Malaysia, 3. Bulgaria; low medium - 1. Vietnam, 2. Ukraine, 3. Georgia; low level - 1. Rwanda, 2. Senegal, 3. Tanzania.

In 2019 the geography of innovation was changed. In the upper echelon there is Switzerland, Sweden and the United States. The US has been leading the innovation rankings for two years. The Netherlands and Germany, along with Singapore in Asia, remain permanent members of the GII top 10. China continues its upward growth moves to the 14th place (from 17th in 2018). China remains the only medium-income economy in the top 30. China's innovative advantages are manifested in numerous areas - in patents (industrial designs and trademarks), high-tech net exports and exports of creative goods. Part of the big innovation drive was transferred from China to India, Russia and Brazil.

According to the World Intellectual Property Organization [2] in 2017 China received the largest number of patent applications - 1.38 million. China is followed by the United States (606956 applications), Japan (318479), the Republic of Korea (204775) and the European patent office (166585). The five largest countries accounted for $84.5 \%$ of the world's patent applications. Germany (67712 applications), India (46582), Russia (36883), Canada (35022) and Australia (28906) are in the top 10. Australia $(+1.8 \%)$, Canada $(+0.8 \%)$ and India $(+3.4 \%)$ saw increase in applications while Germany (-0.3\%) and Russia (-11.3\%) saw declines.

Asia leads the filing of applications for trademarks and industrial designs samples. Revenue generated by the three sectors (trade, education, science, technology and medicine) of the publishing industry in eleven countries amounted to USD 248 billion comprising: 1) China - 202.4 billion USD; 2) USA - 25.9 billion. USD; 3) Germany - 5.8 billion USD; 4) UK -4.7 billion USD. Digital publications generated $28.3 \%$ of the total trade sector revenue in China, $23.5 \%$ in Japan, $18.4 \%$ in Sweden, $13.2 \%$ in Finland and $12.9 \%$ in the United States. [3]

Patent Cooperation Treaty( PCT), the largest international intellectual property (IIP) for filing of the World Intellectual Property Organization (WIPO) application for patent protection in foreign jurisdictions shows key numbers for 2018: PCT national phase entries - 630000 (+2.3\%); PCT applications filed - 253000 (+3.9\%); Applicants - 54341 (+3.8\%); Countries in which PCT applications were filed $-127(+1 \%)$; Share of PCT national phase entries in worldwide non-resident filings $-57.3 \%(+1$ percentage point); Share of women among PCT inventors $-17.1 \%(+0.8$ percentage points) [4].

Russia retains 46th position in GII 2019 in innovative inputs (59th place), outputs - lost three positions since 2017. Growth of rating is seen in the ICT (29th place, +8 positions) and indicators of their application (45th place). Russia lost one position in human capital and research and showed its strengths in tertiary education (14th place), maintained high productivity in patents for inventions (20th place) and utility models (8th place). Russia retains the 3rd position in innovations among medium-income countries.

\section{Literature Review}

The aim of APEC is to increase economic growth rates and prosperity in the region and strengthen Asia-Pacific cooperation by creation of a free and open trade zone, a liberal investment regime by the 2020.

Russia takes active part in APEC projects in which Siberia and the far East play a special role. Territorial proximity of the Russian Far East to the APEC countries determined orientation of its foreign economic relations. Development of the far Eastern region of Russia is today one of the priorities of its state policy. Reorientation of Russia's interests to the East due to the new prospects that open up thanks to mutually beneficial cooperation with APEC countries. 
Russia's participation in APEC allowed to increase the innovative activity of industry, to shift focus to the commercialization of innovative products and high-tech services. R\&D spendings have positive impact on the innovative development of companies [5], introduction of the fifth technology revolution and its priorities [6].

For China APEC is an opportunity to "recognize the new normality, adapt to the new normality, direct the new normality and study the new normality" in ten aspects: economic growth, innovations, production structure, environment, regional coordination, improvement of the quality of living of population, development of mixed ownership, financial development and coordination between market and government $[7,8]$.

\section{Method}

APEC uses statistical and cluster analysis to analyze Russia's innovative position. Statistical analysis is a method of collecting, studying and presenting large amounts of data to identify the main patterns and trends of a certain phenomenon [9]. Statistical analysis includes: statistical observation; sampling; evaluation of relationships, intensity and frequency of changes in objects and phenomena [10].

Cluster analysis is a multi-dimensional statistical procedure for collecting of data containing information on objects sampling and ordering of objects of study in relatively homogenous groups. Cluster analysis allows us to develop a typology (classification) of the objects or phenomena under study, to identify the main schemes of objects (phenomena) grouping, to formulate hypotheses [11, 12].

\section{Result \& Analysis}

Assessment of Russia's innovative position in APEC is carried out with the use of cluster analysis (application package SPSS Statistics, method of analysis "Hierarchical cluster analysis. The average distance between clusters, the square of the Euclidean distance") of the GII indicators WIPO [1]. For the correctness of the cluster analysis the GII indices are converted into the three-point system: " 0 " neutral; " 1 ” - weak; "2" - strong. The analysis revealed the following clusters: 1) multicomponent: nine-cjmponent: Australia and Canada, Brunei Darussalam, Peru, Indonesia, China, Vietnam, Hong Kong, Russia; four-component: Indonesia and Mexico, Philippines, USA; three-component: Hong Kong and Singapore, Malaysia; 2) two-component: Brunei Darussalam and New Zealand; China and Korea; Mexico and Thailand; Peru and Chile; USA and Japan.

Multicomponent nature of clusters is defined by presence of countries with weak ties in a group: Australia and Russia, Hong Kong, Vietnam, China, Indonesia, Peru; Indonesia and USA; Hong Kong and Malaysia. Among the two-component clusters there can be distinguished links between Mexico and Thailand as well as between the US and Japan.

As a result of cluster analysis there are revealed strong links: "Institutions" and "Regulatory environment"; "Human capital and research" and "Researchers, ICT applications".

Analysis of the median $(\mathrm{Me})$ and dispersion $\left(\delta^{2}\right)$ of "Education” dynamics 1989-2017 of APEC countries [13] revealed (Table 1).

Analysis of dynamics of "Education” 1989-2017 in APEC countries revealed consistently high rates in Chinese Taipei, Japan and the United States. Russia's innovative position in APEC reflects high $M e$ values for "Net enrollment Rate, Secondary, Total (\%)" (93.7) and "Gross enrollment Ratio, Tertiary, Total (\%)" (66.9), as well as low values $\delta^{2}$ for "Gross enrollment Ratio, Secondary, Total (\%)" (42.1) and "Net enrollment Rate, Secondary, Total (\%)” (1.9). Competitive advantages of Russia in APEC in the dynamics of "Education" 1989-2017 are associated with "Net enrollment Rate, Secondary, Total (\%)".

As a result of analysis $M e$ and $\delta^{2}$ dynamics of "Information \& Communications" 1989-2017 of APEC countries there is revealed (Table 2). 
Table 1. "Max“ median (Me) and "Min“ dispersion $\left(\delta^{2}\right)$ of "Education” dynamics 1989-2017 of APEC countries.

\begin{tabular}{|c|c|c|c|c|}
\hline Indicator & Countries & Мe, \% & Countries & $\delta^{2}$ \\
\hline School Life & Australia & 19.8 & United States & 0.1 \\
\hline \multirow[t]{4}{*}{ Expectancy (years) } & New Zealand & 16.9 & Hong Kong & 0.1 \\
\hline & Singapore & 16.3 & the Philippines & 0.2 \\
\hline & Hong Kong & 16.2 & Papua New Guinea & 0.2 \\
\hline & Chinese Taipei & 16.2 & Chinese Taipei & 0.4 \\
\hline Gross Enrolment & Australia & 149.5 & Chinese Taipei & 2.7 \\
\hline \multirow{4}{*}{$\begin{array}{l}\text { Ratio, Secondary, } \\
\text { Total (\%) }\end{array}$} & New Zealand & 114.8 & United States & 2.8 \\
\hline & Singapore & 108.1 & Korea & 6.2 \\
\hline & Canada & 102.6 & Japan & 7.8 \\
\hline & Japan & 99.7 & Canada & 15.5 \\
\hline \multirow{5}{*}{$\begin{array}{c}\text { Net Enrolment Rate, } \\
\text { Secondary, Total } \\
(\%)\end{array}$} & Singapore & 99.5 & United States & 1.6 \\
\hline & Japan & 98.7 & Chile & 1.6 \\
\hline & Korea & 94.3 & Russian Federation & 1.9 \\
\hline & Chinese Taipei & 93.7 & Japan & 3.0 \\
\hline & Russian Federation & 93.7 & Malaysia & 4.3 \\
\hline Gross Enrolment & Singapore & 83.9 & Papua New Guinea & 0.5 \\
\hline \multirow{4}{*}{$\begin{array}{c}\text { Ratio, Tertiary, Total } \\
\text { (\%) }\end{array}$} & Korea & 83.3 & the Philippines & 7.9 \\
\hline & United States & 78.9 & Japan & 22.6 \\
\hline & Chinese Taipei & 75.2 & Mexico & 49.4 \\
\hline & Australia & 68.5 & United States & 56.0 \\
\hline
\end{tabular}

Source: calculated from data APEC. All Rights Reserved. URL: http://statistics.apec.org/index.php/key_indicator/kid_result/1. (Accessed: 18.09.2019).

Table 2. "Max" median $(M e)$ and "Min" dispersion $\left(\delta^{2}\right)$ of "Information \& Communications" dynamics 1989-2017 of APEC countries.

\begin{tabular}{ccccc}
\hline Indicator & Countries & Me, \% & Countries & $\delta^{2}$ \\
\hline Internet Users (per & Korea & 69.1 & Papua New Guinea & 10.0 \\
100 inhabitants) & Canada & 65.1 & Indonesia & 80.7 \\
& United States & 63.3 & Thailand & 237.8 \\
& Australia & 63.0 & Peru & 295.5 \\
& New Zealand & 61.8 & Viet Nam & 323.4 \\
Mobile Cellular & the Philippines & 6.7 & Canada & 0.5 \\
Subscriptions (ratio & Thailand & 3.3 & Chinese Taipei & 0.7 \\
to fixed telephone & Malaysia & 2.4 & Korea & 0.7 \\
lines) & Indonesia & 2.3 & Japan & 0.9 \\
& Chile & 2.2 & United States & 1.1 \\
"Networked & Singapore & 5.6 & Brunei Darussalam & 0.0 \\
Readiness Index & United States & 5.6, & Thailand & 1.7 \\
(score)" & Canada & 5.4 & United States & 1.8 \\
& Hong Kong & 5.3 & Japan & 1.9 \\
& Chinese Taipei & 5.3 & Hong Kong & 1.9 \\
\hline
\end{tabular}

Source: calculated from data APEC. All Rights Reserved. URL: http://statistics.apec.org/index.php/key_indicator/kid_result/1. (Accessed: 18.09.2019). 
Analysis of dynamics of "Information \& Communications" 1989-2017 of APEC countries revealed consistently high rates - the United States, catching up - Canada and Thailand. Russia's innovative position in APEC in terms of dynamics of "Information \& Communications" shows an increasing backlog and the risks of losing competitive advantages.

Analysis of Russia's innovative position in APEC in terms of dynamics of "Education" and "Information \& Communications" revealed the risks of losing competitive advantages associated with the high priority of "Net enrollment Rate, Secondary, Total (\%)".

\section{Discussion of Results}

Application of cluster analysis revealed position of Russia in a multicomponent cluster together with Australia, Canada, Brunei Darussalam, Peru, Indonesia, China, Vietnam and Hong Kong. Russia's strong linkage groups are "Institutions" and "Regulatory environment”; "Human capital and research" and "Researchers, ICT applications".

Russia's position in APEC in terms of dynamics of "Education" demonstrates high $\mathrm{Me}$ "Net enrollment Rate, Secondary, Total ( \% )" and "Gross enrollment Ratio, Tertiary, Total ( \% )", as well as low $\delta^{2 ~ " G r o s s ~ e n r o l l m e n t ~ R a t i o, ~ S e c o n d a r y, ~ T o t a l ~(~ \% ~) " ~ a n d ~ " N e t ~ e n r o l l m e n t ~ R a t e, ~ S e c o n d a r y, ~}$ Total (\%)". Russia's innovative position in APEC in terms of dynamics of "Information \& Communications” demonstrates growing backlog from $M e$ the APEC countries.

\section{Conclusion}

Problems of slowing of growth rate of world trade and strengthening of global competition focus on the analysis of innovative position of countries in the format of international cooperation organizations. The absolute world leaders of GII 2019 are the High-income economies - the United States, Germany, Japan, Switzerland, United Kingdom, Netherlands, Sweden, Republic of Korea, France and Canada. APEC includes Canada, Japan and the United States. Among the countries with medium-income economies included in APEC there are China, Mexico, Russia and Thailand.

Russia takes active part in APEC projects keeping the46th position in GII 2019. Growth of ratings in ICT and dynamics of their application. Russia that lost one position in human capital and researches demonstrates strengths in tertiary education, productivity in patents for inventions and utility models. Russia maintains its 3rd position in innovations among the medium-income countries but still loses competitive advantages in terms of dynamics of "Education" and "Information \& Communications” due to high priority of “Net enrollment Rate, Secondary, Total (\%)”.

\section{References}

[1] Global Innovation Index 2019. Creating Healthy Lives - The Future of Medical Innovation. 12 Th Edition. Editors: Soumitra Dutta, Bruno Lanvin, and Sacha Wunsch-Vincent. ISSN 2263-3693. 451 p. https://globalinnovationindex.org.

[2] Intellectual Property Statistics. World Intellectual Property Organization (WIPO). https://www.wipo.int/ipstats/en/

[3] World Intellectual Property Indicators: Filings for Patents, Trademarks, Industrial Designs Reach New Records on Strength in China. Geneva, December 3, 2018. PR/2018/826. https://www.wipo.int/pressroom/en/articles/2018/article_0012.html 
[4] Patent Cooperation Treaty. Yearly Review 2019. The International Patent System. World Intellectual Property Organization. First published 2019. WIPO Publication No. 901E/18. For contact details of WIPO's. External Offices visit: www.wipo.int/about-wipo/en/offices

[5] M. W. Zafar, M. Shahbaz, F. Hou, A. Sinha. From nonrenewable to renewable energy and its impact on economic growth: The role of research \& development expenditures in Asia-Pacific Economic Cooperation countries. Journal of Cleaner Production, 2019, 212: 1166-1178. https://doi.org/10.1016/j.jclepro.2018.12.081

[6] G. Greenleaf, W. Park. South Korea's innovations in data privacy principles: Asian comparisons. Computer Law \& Security Review, 2014, 30 (5): 492-505. https://doi.org/10.1016/j.clsr.2014.07.011

[7] V. V. Smirnov, V. L. Semenov, A. N. Zakharova, E. N. Kadyshev, G. S. Dulina. Innovative management in Russian production companies”. To cite this article: V V Smirnov et al 2019 IOP Conf. Ser.: Mater. Sci. Eng. 483 012060. doi:10.1088/1757-899X/483/1/012060

[8] V. V. Smirnov, D. G. Osipov, A. A. Babaeva, E. V. Grigorieva, E. F. Perfilova. Parity of innovation and digital economy in the Russian management system. Modern Management Trends and the Digital Economy: from Regional Development to Global Economic Growth. (MTDE 2019). Advances in Economics, Business and Management Research, 2019, pp. 22-27. https://doi.org/10.2991/mtde-19.2019.5

[9] J. Lazar, J. H. Feng, H. Hochheiser. Chapter 4: Statistical analysis. Research Methods in Human $\begin{array}{lllll}\text { Computer Interaction } & \text { (Second } & \text { Edition), }\end{array}$ https://doi.org/10.1016/B978-0-12-805390-4.00004-2

[10] S. Schofield. “Impressive statistical analysis”. Science and Public Policy, 1993, 20 (3): 214-215. https://doi.org/10.1093/spp/20.3.214

[11] A. Adolfsson, M. Ackerman, N. C. Brownstein. To cluster, or not to cluster: An analysis of clusterability methods”. Pattern Recognition, 2019, 88: 13-26. https://doi.org/10.1016/j.patcog.2018.10.026

[12] L. P. Fávero, P. Belfiore. Chapter 11: Cluster Analysis. Data Science for Business and Decision Making, 2019; 311-382. https://doi.org/10.1016/B978-0-12-811216-8.00011-2

[13] APEC. All Rights Reserved. http://statistics.apec.org/index.php/key_indicator/kid_result/1 